\title{
An Examination of Cross-Market Arbitrage
}

\author{
Charles Favreau \\ Duquesne University \\ Ryan Garvey \\ Duquesne University
}

We examine cross-market arbitrage in U.S. equity markets. A crossed market occurs when the National Best Bid is greater than the National Best Offer. For calendar year 2018, on all National Market Securities, there are more than 1.8 million market crosses and \$20.2 million in potential arbitrage profits. The mean market cross is for 1.7 cents and 562 shares and lasts 6.6 milliseconds. On a typical day, there are 7,286 crossed quotations. Our findings suggest that cross-market arbitrage in U.S. equities is limited and risky but may exist at times for high-speed traders.

\section{INTRODUCTION}

When securities quote and trade across multiple markets, cross-market arbitrage opportunities can arise. A crossed market occurs when a security's best bid quote in one market is higher than its lowest offer quote in another market (a locked market occurs when a security's best bid quote in one market equals its lowest offer quote in another market). In our paper, we examine cross-market episodes in U.S. equity markets and if potential arbitrage opportunities exist. Quoting and trading in U.S. equities occurs across 13 public stock exchanges and numerous dark venues (see Table 1). To consider cross-market arbitrage, suppose on a given day at 10:00 a.m. that the National Best Bid (NBB) quote for Microsoft (MSFT) on NASDAQ is $\$ 100.01 \times 1000$ shares and that the National Best Offer (NBO) price on NYSE Arca is $\$ 100.00 \times 800$ shares. A securities firm (trader), who has their computers co-located at each exchange facility, could quickly buy 800 shares at the NYSE Arca $\$ 100.00$ offer price and sell 800 shares on NASDAQ at the $\$ 100.00$ bid price, generating a gross profit of $\$ 8$ ( $\$ 0.01 * 800$ shares). Alternatively, the firm (trader) may choose to hit the NBB on NASDAQ and buy 800 shares at $\$ 100.00$ in an offexchange venue. Because profits per trade are small, the strategy needs to occur numerous times throughout the day in order to be viable. The strategy is, of course, not without risk. For example, the securities firm (trader) may only be able to execute one of two trades on a given cross, resulting in unwanted inventory.

While prior research has examined cross-market arbitrage in U.S. equity markets (e.g., Garvey and Murphy, 2006), the research takes place before the implementation of U.S. Securities and Exchange Commission (SEC) Rule 610 of Regulation National Market System (NMS). Among other things, Regulation NMS prohibits market participants from engaging in a pattern of crossing (locking) National Best Bid and Offer (NBBO) protected quotations in the U.S. equity marketplace. Do crossed markets 
occur today? If so, do arbitrage opportunities exist? Our paper provides some insight for answering these questions.

TABLE 1

U.S. EQUITY MARKET VOLUME SUMMARY

\begin{tabular}{lrc}
\hline \multicolumn{1}{c}{ Exchange } & Market Volume & \% of Market Volume \\
\hline NYSE American & $23,221,164$ & $0.32 \%$ \\
NASDAQ BX & $166,789,428$ & $2.31 \%$ \\
NYSE National & $92,104,580$ & $1.28 \%$ \\
CBOE EDGA & $175,286,791$ & $2.43 \%$ \\
CBOE EDGX & $312,312,892$ & $4.33 \%$ \\
Chicago & $35,425,085$ & $0.49 \%$ \\
NYSE & $919,189,486$ & $12.74 \%$ \\
NYSE Arca & $677,792,700$ & $9.40 \%$ \\
NASDAQ & $1,249,625,518$ & $17.32 \%$ \\
IEX & $190,640,379$ & $2.64 \%$ \\
NASDAQ PSX & $58,914,312$ & $0.82 \%$ \\
CBOE BYX & $304,946,590$ & $4.23 \%$ \\
CBOE BZX & $396,123,313$ & $5.49 \%$ \\
NASDAQ/NYSE TRF & $2,610,654,853$ & $36.19 \%$ \\
\hline
\end{tabular}

The table highlights market volume, and percentage of market volume, for the 13 U.S. stock exchanges and the NASDAQ/NYSE Trade Reporting Facilities (i.e., off-exchange "dark" trading) on Friday March 8, 2019.

U.S. equity regulators frown on crossing (locking) quotations in the marketplace because they can create confusion for investors. For example, under market microstructure theory, firms making a market should set a positive bid-ask spread (i.e., offer price greater than the bid price) in order to compensate for adverse selection (Glosten and Milgrom, 1985; Kyle 1985; Easley and O'Hara, 1987), order processing costs (Roll, 1984), and risks incurred with holding inventory (Amihud and Mendelson, 1980; Ho and Stoll, 1981, 1983). However, when trading in the marketplace fragments across numerous venues, crossed (locked) quotations may arise between different market centers for a variety of legitimate reasons including differences in market quoting, trading, and reporting speeds. Regulation NMS requires "selfregulatory organizations" or "SROs" to adopt rules addressing crossing (locking) quotations. The SROs require traders to "reasonably avoid" displaying crossing (locking) quotations, but various exceptions are allowed (e.g., http://finra.complinet.com/en/display/display_main.html?rbid=2403\&element_id=4332).

The remainder of our study proceeds as follows. In Section 2, we discuss the data. The empirical results are in Section 3. First, we examine characteristics of crossed markets. Next, we examine characteristics of stocks that experience more (fewer) crosses. Finally, we examine which exchanges are at the inside prices when crosses occur. Concluding remarks are in Section 4.

\section{DATA}

In order to study crossing quotations in the current U.S. equity market, we use the New York Stock Exchange (NYSE) Daily Trades and Quotes (TAQ) database. We also use the Center for Research in Security Prices (CRSP) database to examine characteristics of stocks that experience a market cross. The TAQ database contains Securities Information Processor (SIP) data. SIP quotation data provide a standard reference price for all U.S. securities traded in the equity markets, and Regulation NMS stipulates using SIP market data for the official NBBO. We examine intraday quoting in U.S. equities from Tuesday, January 2, 2018 through Monday, December 31, 2018 (252 trading days). The publicly available Daily TAQ database consists of intraday trades and quotes, time-stamped to the nanosecond $(1 / 1,000,000,000$ or 10-9), for all securities quoted and traded in U.S. equity markets and reported to a SIP. We focus on the 
"official" SIP NBBO because this is the focus of the SEC. For example, Regulation NMS defines the NBBO as the best bid and best offer calculated and disseminated on a current and continuing basis by a plan processor.

There are five files included in Daily TAQ, and our focus is on the Quote file and NBBO file. The Quote file contains every best bid and offer quote reported to the two Securities Information Processor (SIPs) from each registered stock exchange (13) and the Financial Industry Regulatory Authority (FINRA) Alternative Display Facility (ADF). The NBBO file is an addendum to the Quote file and seeks to provide a continuous record of the NBBO throughout the day based off the data contained in the Quote file. We use the NBBO file and make some standard adjustments in accordance with Holden and Jacobsen (2014). After making these adjustments, we compute an adjusted NBBO, for each nanosecond of the day, for all NMS securities, over the sample period. While NASDAQ-listed securities are timestamped to the nanosecond, all other exchange-listed securities are time-stamped to the microsecond with three trailing zeros. Thus, we calculate results at the nanosecond when possible and round to the microsecond $(1 / 1,000,000$ or $10-6)$ to tabulate.

\section{EMPIRICAL RESULTS}

\section{Crossed Market Characteristics}

In Table 2, we highlight characteristics about NBBO crossed quotations and the overall market for all NMS securities, during 9:30 a.m. - 4:00 p.m., over the calendar year 2018. In total, there are 1,836,034 crossed NBBO quotations. The mean (median) cross is for 1.7 cents $(1$ cent). When a market cross occurs, the mean number of shares at the National Best Bid (Offer) is 653 (686). Thus, the average crossmarket arbitrage profit is approximately $\$ 11.01\left(\$ 0.017^{*} 653\right)$ and, in total, there are approximately $\$ 20,214,734$ in potential cross-market arbitrage profits over one-year.

While cross-market arbitrage opportunities may exist at certain times, the profits from this strategy are not without risk. For example, market crosses are fleeting in nature. The mean (median) duration of a cross is 6.6 milliseconds ( 0.3 milliseconds). Thus, cross-market arbitrage strategies would require colocated computers at multiple exchange facilities. Even still, it is highly unlikely that a single trader (firm) would be able to capture all market crosses due to competitive market forces. Cross-market arbitrage also entails risk. For example, suppose the NBB on NYSE National is $\$ 50.01$ X 500 shares and the NBO on CBOE BYX is $\$ 50.00 \times 400$ shares. If a firm (trader) simultaneously submits a marketable buy order to CBOE BYX for $\$ 50.00$ and 400 shares, and a marketable sell order to NYSE National for $\$ 50.01$ and 400 shares, only one of the two orders may fill thereby resulting in an unintended open long (short) position of 400 shares. Finally, trading costs are an important consideration (e.g., Garvey and Murphy, 2006) as these will lower cross-market arbitrage profits.

TABLE 2

\section{CROSSED MARKET CHARACTERISTICS}

\begin{tabular}{lcccc}
\hline & $\begin{array}{c}\text { Cross-Market } \\
\text { Mean }\end{array}$ & Market Mean & $\begin{array}{c}\text { Cross-Market } \\
\text { Median }\end{array}$ & Market Median \\
\hline Spread & -0.017 & 0.039 & -0.01 & 0.010 \\
Bid size & 653 & 17.69 & 100 & 4.50 \\
Offer size & 686 & 17.99 & 100 & 4.59 \\
Duration & $0: 00: 00.006603$ & & $0: 00: 00.000332$ & \\
\hline
\end{tabular}

The table results highlight characteristics about NBBO crossed quotations and the overall market, for all NMS securities, during 9:30 a.m. - 4:00 p.m., over the calendar year 2018 (252 trading days). In total, there are 1,836,034 crossed NBBO quotations. Results are winsorized at the 2 nd and 98th percentile. 


\section{Crossed Markets and Stock Characteristics}

In Table 3, we examine characteristics of all NMS securities that experience a crossed market. Traders (firms) may be able to anticipate cross-market arbitrage opportunities on certain stocks. First, we sort NMS securities into deciles according to their number of crossed market episodes. Using the CRSP database, we compute for each grouping an average market capitalization on January 1, 2018, an average monthly turnover (shares traded/shares outstanding) over the one-year period ending January 1, 2018, and an average price on January 1,2018 . The results indicate that securities that experience most crossed markets have larger market capitalization, greater turnover, and higher prices. The fact that crossed markets are more prevalent on higher priced securities highlights additional risk involved with implementing cross-market arbitrage strategies. For example, the average price for securities with the lowest (highest) number of market crosses is $\$ 35.16$ ( $\$ 80.28)$.

TABLE 3

\section{CROSSED MARKETS AND STOCK CHARACTERISTICS}

\begin{tabular}{lccc}
\hline & Mkt. Cap. (000's) & Turnover & Price \\
\hline Lowest & 284,353 & 1.93 & $\$ 35.16$ \\
2 & 365,979 & 1.55 & $\$ 30.30$ \\
3 & 547,256 & 1.44 & $\$ 26.59$ \\
4 & 806,774 & 1.87 & $\$ 28.40$ \\
5 & $1,056,993$ & 2.01 & $\$ 34.65$ \\
6 & $1,153,363$ & 2.36 & $\$ 28.03$ \\
7 & $1,603,793$ & 2.69 & $\$ 29.95$ \\
8 & $2,745,020$ & 3.26 & $\$ 45.10$ \\
9 & $5,938,120$ & 3.79 & $\$ 51.99$ \\
Highest & $33,734,366$ & 4.82 & $\$ 80.28$ \\
\hline
\end{tabular}

The table results highlight characteristics of all NMS securities that experience a crossed market, during 9:30 a.m. 4:00 p.m., over the calendar year 2018. NMS securities are sorted into deciles according to their number of crossed market episodes. Mkt. Cap (000's) is the average market capitalization for each security on January 1, 2018, Turnover is the average monthly turnover (shares traded/shares outstanding) for each security over the one-year period ending January 1, 2018, and Price is the average price for each security over the one-year period ending January 1, 2018. Results are winsorized at the 2nd and 98th percentile.

\section{Crossed Markets and Exchange Combinations}

Capturing market crosses requires trading in multiple market centers. In Table 4, we highlight the percentage of time an exchange combination is at the best bid and best offer when the market is crossed. NASDAQ and NYSE Arca appear most frequently at the best bid and best offer during crossed markets. For example, on $7.876 \%$ of the crosses, NASDAQ is at the best bid and NYSE Arca is at the best offer. On $7.673 \%$ of the crosses, NYSE Arca is at the best bid and NASDAQ is at the best offer. Of course, a firm (trader) need not hit the publicly viewable exchange prices in order to take advantage of a NBBO market cross. The second leg of the round-trip may occur over an off-exchange "dark" trading venue. 
TABLE 4

INSIDE EXCHANGE COMBINATION DURING CROSSED MARKETS

\begin{tabular}{|c|c|c|c|c|c|c|c|c|c|c|c|c|c|}
\hline \multirow[b]{3}{*}{ Bid Exchange } & \multicolumn{13}{|c|}{ Offer Exchange } \\
\hline & & & & & & $\mathrm{CHX}$ & NYSE & NYSE & NASD & IEX & NASD & $\mathrm{CBOE}$ & CBOE \\
\hline & Amer & BX & Natnl & EDGA & EDGX & & & Arca & & & PSX & BYX & BZX \\
\hline NYSE Amer & & 0.009 & 0.003 & 0.016 & 0.091 & 0.004 & 0.054 & 0.296 & 0.249 & 0.008 & 0.012 & 0.016 & 0.113 \\
\hline NASD BX & 0.012 & & 0.008 & 0.012 & 0.090 & 0.430 & 0.231 & 0.357 & 0.244 & 0.070 & 0.015 & 0.021 & 0.198 \\
\hline NYSE Natnl & 0.004 & 0.005 & & 0.007 & 0.034 & 0.028 & 0.055 & 0.105 & 0.148 & 0.012 & 0.008 & 0.008 & 0.061 \\
\hline CBOE EDGA & 0.012 & 0.015 & 0.006 & & 0.085 & 1.226 & 0.122 & 0.216 & 0.242 & 0.219 & 0.017 & 0.014 & 0.278 \\
\hline CBOE EDGX & 0.091 & 0.092 & 0.040 & 0.092 & & 1.077 & 0.930 & 2.040 & 1.834 & 0.637 & 0.204 & 0.063 & 0.699 \\
\hline CHX & 0.004 & 0.423 & 0.033 & 1.223 & 1.036 & & 0.419 & 3.123 & 1.515 & 0.026 & 1.221 & 0.325 & 1.448 \\
\hline NYSE & 0.049 & 0.226 & 0.065 & 0.115 & 0.871 & 0.441 & & 1.998 & 2.943 & 0.600 & 0.162 & 0.201 & 2.013 \\
\hline NYSE Arca & 0.272 & 0.332 & 0.105 & 0.197 & 1.858 & 3.171 & 1.959 & & 7.673 & 1.371 & 0.496 & 0.342 & 3.732 \\
\hline NASD & 0.219 & 0.233 & 0.158 & 0.248 & 1.805 & 1.548 & 2.984 & 7.876 & & 1.100 & 0.488 & 0.310 & 3.448 \\
\hline IEX & 0.007 & 0.072 & 0.013 & 0.254 & 0.675 & 0.024 & 0.623 & 1.427 & 1.155 & & 0.142 & 0.129 & 0.746 \\
\hline NASD PSX & 0.014 & 0.018 & 0.010 & 0.020 & 0.221 & 1.238 & 0.191 & 0.546 & 0.535 & 0.141 & & 0.027 & 0.491 \\
\hline CBOE BYX & 0.014 & 0.024 & 0.009 & 0.012 & 0.059 & 0.322 & 0.204 & 0.382 & 0.337 & 0.111 & 0.025 & & 0.149 \\
\hline CBOE BZX & 0.107 & 0.203 & 0.066 & 0.293 & 0.705 & 1.544 & 2.144 & 3.982 & 3.514 & 0.731 & 0.498 & 0.156 & \\
\hline
\end{tabular}

The table results highlight the percentage of time an Exchange combination is at the best bid and best offer when the NBBO is crossed. The results are for all NMS securities, during 9:30 a.m. - 4:00 p.m., over the calendar year 2018. All numbers are in percentages.

\section{CONCLUSION}

Trading in U.S. equity markets occurs across 13 stock exchanges and numerous ("dark") offexchange venues. When securities quote and trade over multiple separate venues, cross-market arbitrage opportunities can arise. A crossed market occurs when the NBB is greater than the NBO. Although SEC Rule 610 of Regulation NMS prohibits market participants from engaging in a pattern of crossing (locking) the NBBO in the U.S. equity marketplace, market crosses still occur. We study quoting in U.S. equity markets for calendar year 2018 and find that, on average, 7,286 market crosses occur per day and more than 1.8 million market crosses occur per year.

Capturing market crosses is not trivial. Crosses are fleeting in nature lasting, on average, 6.6 milliseconds. The median market cross time is 332 microseconds. Thus, cross-market arbitrage is a computer-driven (rather than human-driven) trading strategy. However, for firms (traders) with colocation operations at the multiple market centers, capturing market crosses may be a viable strategy. For example, while we find that crosses last milliseconds on average, some markets now process and report their quotes and trades in nanoseconds (e.g., NASDAQ).

Cross-market arbitrage strategies require trading in multiple market centers and we find that NASDAQ and NYSE Arca appear most frequently at the best bid and best offer during crossed markets. Cross-market arbitrage also requires numerous trades per day in order to be a profitable strategy. For example, the average market cross is for 1.7 cents and 653 shares. Crossed markets are more likely to occur on large capitalization stocks with more turnover and higher prices.

Our paper examines cross-market arbitrage in the U.S. equity market. Cross-market arbitrage can also exist with correlated assets across different U.S. financial markets (e.g., future markets and equity markets). In addition, cross-market arbitrage can occur across different international markets (e.g., dual listed securities in different country exchanges). These other markets would be interesting areas for future research exploration. 


\section{REFERENCES}

Amihud, Y. and Mandelson, H. (1980). Dealership market: Market making with inventory. Journal of Financial Economics, 8, 31-53.

Easley, D., \& O'Hara, M. (1987). Price, trade size, and information in securities market. Journal of Financial Economics, 19, 69-90.

Garvey, R., \& Murphy, A. (2006). Crossed Markets: Arbitrage opportunities in Nasdaq stocks. Journal of Alternative Investments, 9, 46-58.

Glosten, L., \& Milgrom, P. (1985). Bid, ask, and transaction prices in a specialist market with heterogeneously informed traders, Journal of Financial Economics 14, 71-100.

Ho, T., \& Stoll, H. (1981). Optimal dealer pricing under transactions and return uncertainty. Journal of Financial Economics, 9, 47-73.

Ho, T., \& Stoll, H. (1983). The dynamics of dealer markets under competition. Journal of Finance 38, 1053-1074.

Holden, C.W., \& Jacobsen, S. (2014). Liquidity measurement problems in fast, competitive markets: Expensive and cheap solutions, Journal of Finance, 69, 1747-1784.

Intercontinental Exchange Company (2016). Daily TAQ Client Specification. Retrieved from http://www.nyxdata.com/data-products/daily-taq

Kyle, A. (1985. Continuous auctions and insider trading. Econometrica, 53, 1315-1335.

Roll, R. (1984). A simple implicit measure of the effective bid-ask spread in an efficient market. Journal of Finance, 39, 1127-1139.

U.S. Securities and Exchange Commission (SEC) (2005). Regulation NMS. Retrieved from https://www.sec.gov/rules/final/34-51808.pdf 